\title{
Efeito do tamanho de partícula e da altura de colheita das plantas de milho (Zea mays L.) sobre as perdas durante o processo fermentativo e o período de utilização das silagens
}

\author{
Mikael Neumann², Paulo Roberto Frenzel Mühlbach ${ }^{3}$, José Laerte Nörnberg ${ }^{4}$, João Restle ${ }^{5}$, \\ Paulo Roberto Ost ${ }^{6}$
}

\author{
1 Parte da tese de Doutorado do primeiro autor. \\ ${ }^{2}$ Curso de Medicina Veterinária da UNICENTRO - Rua Simeão Camargo Varela de Sá, 03, CEP: 85040-080, Centro de Ciências Agrárias e \\ Ambientais da Universidade Estadual do Centro-Oeste, Guarapuava, PR. Pesquisador do NUPRAN (Núcleo de Produção Animal). \\ ${ }^{3}$ Departamento de Zootecnia da UFRGS. \\ ${ }^{4}$ Departamento de Tecnologia de Alimentos da UFSM. \\ ${ }^{5}$ Curso de Pós-Graduação em Zootecnia da UFG. Pesquisador do CNPq. \\ ${ }^{6}$ Departamento de Medicina Veterinária da UNICENTRO.
}

RESUMO - O experimento foi conduzido com o objetivo de avaliar o efeito do tamanho de partícula (pequena de 0,2 a 0,6 $\mathrm{cm}$ ou grande de 1,0 a 2,0 cm) e da altura de corte das plantas de milho para ensilagem (baixo: 15,2 cm ou alto: $38,6 \mathrm{~cm}$ ) sobre as perdas e o valor nutritivo das silagens. Foram avaliadas as seguintes silagens: silagem de partícula pequena com altura de corte baixo; silagem de partícula grande com altura de corte baixo; silagem de partícula pequena com altura de corte alto; e silagem de partícula grande com altura de corte alto. Não houve efeito significativo das interações altura de colheita das plantas $\times$ tamanho de partícula sobre as perdas de MS, PB e FDN. Influências significativas das interações altura de colheita das plantas $\times$ estrato no silo e tamanho de partícula $\times$ estrato no silo foram observadas, respectivamente, sobre as perdas de MS e PB. As silagens obtidas com corte alto $(38,6 \mathrm{~cm})$ no estrato inferior apresentaram maiores perdas $(4,91 \%)$ em relação ao estrato superior no silo $(2,67 \%)$ e às silagens obtidas com corte baixo $(15,2 \mathrm{~cm})$, independentemente do estrato no silo. Na análise das perdas de PB, os maiores valores foram observados em silagens de partículas pequenas no estrato superior $(18,96 \%)$ e em silagens de partículas grandes no estrato inferior $(18,68 \%)$, comparativamente às silagens com partículas pequenas no estrato inferior $(11,52 \%)$ e às silagens de partículas grandes no estrato superior (17,54\%). A silagem com partícula grande resultou em maiores perdas físicas na desensilagem.

Palavras-chave: estrato no silo, perdas físicas, perdas químicas, proteína bruta, silagem de milho

\section{Effect of particle size and cutting height of corn (Zea mays L.) on losses of silages during the fermentation process and utilization period}

\begin{abstract}
This trial evaluated the effect of particle size (small: between 0.2 and $0.6 \mathrm{~cm}$ or large: between 1.0 and $2.0 \mathrm{~cm}$ ) and cutting height (low cut: $15.2 \mathrm{~cm}$ or high cut: $38.6 \mathrm{~cm}$ ) of the corn plant on losses and nutritional value of silages Treatments were: $T_{1}$ - small particle size with low cutting height; $T_{2}$ - large particle size with low cutting height; $T_{3}-$ small particle size with high cutting height; and $\mathrm{T}_{4}$ - large particle size with high cutting height. No significant interaction was observed between cutting height and particle size for the following response variables: DM loss, CP loss, and NDF loss. Significant interaction was observed between cutting height and silo stratum and between particle size and silo stratum for the variables DM loss and CP loss, respectively. The high cutting silages $(38.6 \mathrm{~cm})$ on the inferior stratum showed higher losses (4.91\%) compared to the superior silo stratum $(2.67 \%)$ and low cutting silages $(15,2 \mathrm{~cm})$ regardless of the silo stratum. Greater CP losses were observed on the silages with small particle size on the superior stratum $(18.96 \%)$ and on the silages with large particle size on the inferior stratum (18.68\%) compared to silages with small particle size on the inferior stratum (11.52\%) and silages with large particle size on the superior stratum (17.54\%). Silages with large particle size resulted in higher physical losses at feeding-out.
\end{abstract}

Key Words: chemical losses, corn silage, crude protein, physical losses, silo stratum

\section{Introdução}

As perdas durante os processos da fermentação, relacionadas às alterações químico-bromatológicas da forra- gem ensilada, têm sido enfocadas em vários estudos. Esse tipo de perda depende das características da planta forrageira e está associado às práticas de implantação, manejo e colheita das lavouras e ao sistema de armazenamento. Por 
outro lado, segundo Balsalobre et al. (2001), outros tipos de perdas da silagem, como as perdas físicas promovidas pelo efluente, pela produção de gases durante a fermentação no silo e pela retirada da forragem e sua distribuição aos animais, tem grande importância, pois oneram os custos do sistema de produção e podem, inclusive, inviabilizá-lo economicamente.

Durante o processo de produção, vários fatores influenciam a obtenção de silagem com alta qualidade, entre eles, a produtividade da lavoura e a conservação adequada do material ensilado. Conforme revisão de Mühlbach (1999), os processos que ocorrem no interior do silo são ocasionados por características inerentes à planta ensilada (processos de origem endógena que englobam a respiração, a lise celular, a proteólise e a degradação enzimática de oligossacarídeos a açúcares simples), à ação de microrganismos (ação aeróbia de fungos, leveduras e de enterobactérias ou anaeróbia controlada por lactobacilos ou por bactérias clostrídicas) e/ou a reações químicas (como a reação de Maillard ou a hidrólise da hemicelulose da planta, fator fundamental para ocorrência de perdas e/ou a manutenção da qualidade da silagem). Esses processos, segundo esse autor, dependem das condições do meio ambiente no interior do silo.

Segundo McDonald (1991), as perdas controláveis originadas por efluentes, re-fermentação, degradação aeróbia no armazenamento e na desensilagem podem representar até $31 \%$ da massa ensilada, enquanto as perdas inevitáveis originadas pela pré-secagem, pela respiração celular e pela fermentação indesejável podem atingir $15 \%$. Logo, a viabilidade econômica do uso de silagem de milho na alimentação de ruminantes depende dos cuidados na minimização das perdas que podem ocorrer nas diferentes etapas de produção e que são controláveis pelos procedimentos técnicos adotados, uma vez que se trata de um cultivo de custo relativamente alto de implantação, colheita e processamento.

Assim, a eficiência dos sistemas de conservação de forragem não deve ser avaliada somente pelo valor nutritivo do produto final, mas também pelas perdas que ocorrem da colheita das plantas até a alimentação dos animais. A mensuração das perdas de matéria seca e dos demais nutrientes na ensilagem é difícil e exige metodologias específicas e precisas, pois depende da coleta de amostras que representem a condição do armazenamento. Além disso, a mensuração se baseia no desaparecimento de matéria seca ou energia durante os processos de ensilagem e desensilagem (McDonald, 1991).

No Brasil poucas pesquisas quantificaram as perdas absolutas que ocorrem na ensilagem e grande parte desses estudos não representa a real situação do produtor, pois a maioria das pesquisas foi conduzida utilizando-se silos laboratoriais (comparando efeitos de tratamentos) em condições que não refletem a realidade do processo. Em especial, não se dispõem de dados sistematicamente produzidos sobre as perdas durante a ensilagem e desensilagem do material, processos que, segundo McDonald et al. (1991), podem ocasionar até $20 \%$ de perdas adicionais.

Segundo Evangelista et al. (2004), durante o processo fermentativo, ocorrem perdas de matéria seca e de energia de forma variada, em decorrência da colonização de bactérias ácidoláticas que se desenvolvem na massa ensilada, determinando perdas de energia de até $1,7 \%$ e de matéria seca de até $24 \%$. Balsalobre et al. (2001) afirmaram que as perdas físicas podem atingir diariamente $3 \%$ da MS após a abertura do silo para alimentação dos animais e decorrem da exposição ao ar na massa ensilada, que pode promover degradação microbiana

$\mathrm{Na}$ cultura do milho são vários os aspectos que causam variações na qualidade da silagem, como a escolha do híbrido, o estádio de maturação da planta, além de aspectos agronômicos como tipo de solo e clima. Na produção das silagens, aspectos relacionados ao tamanho de partículas e à altura de colheita de plantas afetam o grau de compactação, pois, conforme descrito por Senger et al. (2005), quanto menor a partícula e maior a altura de colheita, melhor a compactação e,conseqüentemente, a condição de anaerobiose, que é decisiva no processo de conservação. Contudo, na prática, procura-se também maior rapidez no processo, que é facilitado quando a ensiladeira é regulada para maior tamanho de partícula do material e maior altura de corte. Assim, é de grande interesse prático a avaliação criteriosa das perdas que podem ocorrer em ambos os casos.

Este trabalho foi realizado com o objetivo de avaliar o efeito do tamanho de partícula e da altura de corte das plantas de milho na ensilagem sobre as perdas e o valor nutritivo da silagem de milho durante o processo fermentativo e o período de utilização.

\section{Material e Métodos}

O experimento foi conduzido nas instalações do Núcleo de Produção Animal (NUPRAN) do Centro de Ciências Agrárias e Ambientais da Universidade Estadual do CentroOeste(UNICENTRO), em Guarapuava-PR, no período de 15 de outubro de 2004 a 15 de dezembro de 2005.

O clima da região de Guarapuava é o Cfb (subtropical mesotérmico úmido), sem estação seca, com verões frescos e inverno moderado, conforme a classificação de Köppen, 
em altitude de aproximadamente $1.100 \mathrm{~m}$, precipitação média anual de $1.944 \mathrm{~mm}$, temperatura média mínima anual de $12,7^{\circ} \mathrm{C}$, temperatura média máxima anual de $23,5^{\circ} \mathrm{C}$ e umidade relativa do ar de $77,9 \%$.

O solo da área experimental, classificado como Latossolo Bruno Típico, em outubro de 2004, apresentou as seguintes características químicas (perfil de 0 a $20 \mathrm{~cm}$ ): $\mathrm{pH}$ $\mathrm{CaCl}_{2}$ 0,01M: 4,7; P: $1,1 \mathrm{mg} \mathrm{dm}^{3-} ; \mathrm{K}^{+}: 0,2 \mathrm{cmol}_{\mathrm{c}} \mathrm{dm}^{3-} ; \mathrm{MO}$ : $2,62 \% ; \mathrm{Al}^{3+}: 0,0 \mathrm{cmol}_{\mathrm{c}} \mathrm{dm}^{3-} ; \mathrm{H}^{+}+\mathrm{Al}^{3+}: 5,2 \mathrm{cmol}_{\mathrm{c}} \mathrm{dm}^{3-}$; $\mathrm{Ca}^{2+}: 5,0 \mathrm{cmol}_{\mathrm{c}} \mathrm{dm}^{3-} ; \mathrm{Mg}^{2+}: 5,0 \mathrm{cmol}_{\mathrm{c}} \mathrm{dm}^{3-}$ e saturação de bases: $67,3 \%$.

Para as variáveis relativas aos dados de perdas durante o processo fermentativo e o período de utilização das silagens, foram avaliados os efeitos de dois tamanhos de partícula (pequena entre 0,2 e $0,6 \mathrm{~cm}$ e a grande entre 1,0 e 2,0 cm) e de duas alturas de corte das plantas (baixo em $15,2 \mathrm{~cm}$ e alto em $38,6 \mathrm{~cm}$ ), em esquema fatorial $2 \times 2$ : silagem de partícula pequena com altura de corte baixo; silagem de partícula grande com altura de corte baixo; silagem de partícula pequena com altura de corte alto; e silagem de partícula grande com altura de corte alto.

As silagens foram confeccionadas com o híbrido de milho P-30S40, de caráter silageiro de porte alto, e produzidas em uma área de 2 ha, subdivida em 12 faixas de $1.700 \mathrm{~m}^{2}$. A lavoura foi estabelecida em 22 de outubro de 2004, em sistema de plantio direto. No plantio, utilizou-se espaçamento entre linhas de $0,8 \mathrm{~m}$, profundidade de semeadura de $4 \mathrm{~cm}$ e distribuição de cinco sementes por metro linear.

Procedeu-se à adubação de base de $350 \mathrm{~kg} / \mathrm{ha}$ com o fertilizante 08-30-20 ( $\left.\mathrm{N}-\mathrm{P}_{2} \mathrm{O}_{5}-\mathrm{K}_{2} \mathrm{O}\right)$, conforme recomendações da Comissão de Fertilidade do Solo - RS/SC (1995). Após 35 dias do plantio, efetuou-se a adubação de $\mathrm{N}$ em cobertura com $120 \mathrm{~kg} / \mathrm{ha}$, na forma de uréia. No manejo da cultura até 30 dias após a emergência das plantas, foram aplicados herbicida adicionado de óleo mineral e defensivo para controle da lagarta do cartucho.

A colheita das plantas de milho, no estádio de grão pastoso, ocorreu nos dias 7 a 8 de março de 2005, com auxílio de uma ensiladeira. De forma alternada, seis faixas de cultivo de milho foram colhidas com regulagem para tamanho de partícula pequena e seis faixas para tamanho de partícula grande, variando a cada três faixas à altura de corte baixa ou alta.

O material colhido de cada faixa de cultivo foi transportado, depositado em local previamente nivelado e drenado e compactado com auxílio de um trator, em silos do tipo semitrincheira com dimensões de 1,6 $\mathrm{m}$ de largura, $10 \mathrm{~m}$ de comprimento e $0,8 \mathrm{~m}$ de altura. Os silos foram completamente vedados e protegidos com lona de polietileno de três camadas $(200 \mu)$. Desse modo, considerando os aspectos avaliados, foram confeccionados 12 silos com capacidade individual de aproximadamente $8.000 \mathrm{~kg}$.

Durante a ensilagem, foram locados oito bags no perfil de cada silo contendo material original com peso conhecido. A designação de bag refere-se a um saco de náilon maleável $100 \%$ poliamina, com poros de 85 micrômetros, dimensões de 12 x $50 \mathrm{~cm}$ de diâmetro e comprimento, respectivamente, com capacidade média de $2.000 \mathrm{~g}$, com nível de compactação prévio aproximado de $350 \mathrm{~kg} / \mathrm{m}^{3}$ de matéria verde (material original). Os oito bags foram dispostos em quatro pontos do silo (dois na parte inicial, quatro na parte intermediária e dois na parte final), quatro bags dispostos na porção inferior e quatro na porção superior.

Cada bag foi identificado, pesado individualmente vazio e novamente pesado após seu enchimento com material original em balança digital com precisão de um grama. A compactação final da forragem contida nos bags foi efetuada no silo pela ação do trator, buscando-se a mesma compactação entre forragem contida no bag e no silo. Para vedar os bags, foram utilizados lacres do tipo braçadeira flexível de PVC.

No momento de inserção dos bags em cada um dos silos, amostras (homogêneas e representativas) da forragem original de cada tratamento foram coletadas para présecagem para análises posteriores. A abertura dos silos ocorreu 150 dias após a ensilagem. O resgate dos bags foi feito quando ocorreu seu aparecimento no painel dos silos no decorrer de 84 dias de desensilagem para alimentação de animais em confinamento nos quatro pontos pré-determinados dos silos - partes inicial, intermediária (duas amostras) e final.

Parte das amostras de silagens contidas em cada bag foi pesada e pré-seca em estufa de ar forçado a $55^{\circ} \mathrm{C}$ por 72 horas para determinação do teor de matéria parcialmente seca e triturada em moinho tipo Wiley com peneira de malha de $1 \mathrm{~mm}$.

Nas amostras pré-secas, determinaram-se os teores de MS total, PB, cinzas e MO, conforme AOAC (1995). Também foram determinados os teores de FDN, conforme descrito por Van Soest et al. (1991), utilizando-se $\alpha$-amilase termoestável.

As perdas de nutrientes (MS, PB e FDN) foram expressas pela diferença de gradientes entre material original e material desensilado, associada ao peso dos bags na ensilagem e na desensilagem, conforme estrato no silo (porção inferior: profundidade de 0 a $40 \mathrm{~cm}$ ou porção 
superior: profundidade de 40 a $80 \mathrm{~cm}$ ). Os intervalos de desensilagem ocorreram entre agosto e novembro de 2005, com períodos correspondentes de 20 a 22 dias cada um. As perdas físicas foram determinadas pela retirada e pesagem das sobras de silagem deteriorada nos silos e das sobras de silagem nos cochos de alimentação dos animais.

Após a abertura dos silos, durante os períodos de desensilagem, foram coletadas amostras, que foram prensadas utilizando-se uma prensa hidráulica para extração do suco e determinação do pH e do nitrogênio amoniacal, conforme técnica descrita pela AOAC (1995).

Durante o período de desensilagem dos silos do tipo semitrincheira, semanalmente foram realizadas medições da temperatura do meio ambiente e da silagem nos estratos inferior e superior dos silos, a uma profundidade de $7 \mathrm{~cm}$ na massa estruturada na face dos silos. Essas medidas foram tomadas diariamente às $16 \mathrm{~h} 30$.

A eficiência de compactação da massa $\left(\mathrm{kg} / \mathrm{m}^{3}\right)$ na base seca ou verde foi avaliada utilizando-se anel metálico de $10 \mathrm{~cm}$ de diâmetro e $15 \mathrm{~cm}$ de altura, introduzido sob pressão nos estratos inferior e superior da massa estruturada da face dos silos para retirada de um volume definido de silagem compactada e subseqüente pesagem e amostragem.

O experimento foi conduzido segundo delineamento de blocos inteiramente casualizados com três repetições utilizando-se parcelas subsubdivididas, em esquema fatorial $2 \times 2 \times 4$, composto de dois tamanhos de partículas (pequena e grande), duas alturas de colheita (baixa e alta) e quatro períodos de avaliação durante a desensilagem: o primeiro entre 24 de agosto e 14 de setembro; o segundo entre 15 de setembro e 05 de outubro; o terceiro entre 6 e 26 de outubro; e o quarto entre 27 de outubro e 16 de novembro, conforme modelo estatístico a seguir:

$$
\begin{gathered}
\mathrm{Y}_{\mathrm{ijk}}=\mu+\mathrm{TP}_{\mathrm{i}}+\mathrm{AC}_{\mathrm{j}}+(\mathrm{TP} * \mathrm{AC})_{\mathrm{ij}}+\mathrm{R}_{\mathrm{l}}(\mathrm{TP} * \mathrm{AC})_{\mathrm{ij}}+\mathrm{P}_{\mathrm{k}}+ \\
(\mathrm{TP} * \mathrm{P})_{\mathrm{ik}}+(\mathrm{AC} * \mathrm{P})_{\mathrm{ik}}+(\mathrm{TP} * \mathrm{AC} * \mathrm{D} *)_{\mathrm{ijk}}+\mathrm{LS}_{1}+(\mathrm{TP} * \mathrm{LS})_{\mathrm{il}} \\
+(\mathrm{AC} * \mathrm{LS})_{\mathrm{il}}+(\mathrm{TP} * \mathrm{AC} * \mathrm{LS} *)_{\mathrm{ijl}}+(\mathrm{P} * \mathrm{LS})_{\mathrm{kl}}+ \\
(\mathrm{TP} * \mathrm{P} * \mathrm{LS})_{\mathrm{jk} 1}+(\mathrm{AC} * \mathrm{P} * \mathrm{LS})_{\mathrm{ikl}}+\mathrm{E}_{\mathrm{ijkl}},
\end{gathered}
$$

em que $\mathrm{Y}_{\mathrm{ijkl}}=$ variáveis dependentes; $\mu=$ média geral de todas as observações; $\mathrm{TP}_{\mathrm{i}}=$ efeito do tamanho da partícula da silagem de ordem "i", em que 1 = pequena e 2 = grande; $\mathrm{AC}_{\mathrm{j}}=$ efeito da altura de colheita de ordem " $\mathrm{j}$ ", em que $1=$ baixa e 2 =alta; $\left(\mathrm{TP}^{*} \mathrm{AC}\right)_{\mathrm{ij}}=$ efeito da interação i-ésima tamanho de partícula $\times$ j-ésima altura de colheita; $\mathrm{R}_{\mathrm{l}}(\mathrm{TP} * \mathrm{AC})_{\mathrm{ij}}=$ efeito aleatório com base na repetição dentro da combinação $\left(\mathrm{TP}^{*} \mathrm{AC}\right)_{\mathrm{ij}}$ (Erro a); $\mathrm{P}_{\mathrm{k}}=$ efeito do período de coleta de amostras de silagem durante a desensilagem de ordem "k", em que 1 = primeiro período, 2 = segundo período, $3=$ terceiro período e $4=$ quarto período; $(\mathrm{TP} * \mathrm{P})_{\mathrm{ik}}=$ efeito da interação i-ésima tamanho de partícula $\times \mathrm{k}$-ésimo período de coleta na desensilagem; $(\mathrm{AC} * \mathrm{P})_{\mathrm{ik}}=$ efeito da interação $\mathrm{j}$-ésima altura de colheita $\times \mathrm{k}$-ésimo período de coleta de amostras de silagem na desensilagem; $\left(\mathrm{TP}^{*} \mathrm{AC} \mathrm{CP}^{*}\right)_{\mathrm{ijk}}=$ efeito da interação $\mathrm{i}$-ésimo tamanho de partícula $\times$ j-ésima altura de colheita $\times$ k-ésimo período de coleta de amostras de silagem na desensilagem; $\mathrm{LS}_{1}=$ efeito do estrato no silo de ordem "l", em que 1 = estrato inferior e 2 = estrato superior; $(\mathrm{TP} * \mathrm{LS})_{\mathrm{il}}=$ efeito da interação i-ésimo tamanho de partícula $\times 1$-ésima estrato no silo; $(\mathrm{AC} * \mathrm{LS})_{\mathrm{il}}=$ efeito da interação j-ésima altura de colheita $\times 1$-ésimoestrato no silo; $(\mathrm{TP} * \mathrm{AC} * \mathrm{LS} *)_{\mathrm{ijl}}=$ efeito da interação i-ésimo tamanho de partícula $\times \mathrm{j}$-ésima altura de colheita $\times 1$-ésimo estrato no silo; $\left(\mathrm{P}^{*} \mathrm{LS}\right)_{\mathrm{kl}}=$ efeito da interação k-ésimo período de coleta na desensilagem $\times 1$-ésimo estrato no silo; $(\mathrm{TP} * \mathrm{P} * \mathrm{LS})_{\mathrm{jkl}}$ $=$ eeito da interação i-ésimo tamanho de partícula $\times$ k-ésimo período de coleta de amostras de silagem na desensilagem e com o l-ésimo estrato no silo; $\left(\mathrm{AC} * \mathrm{P}^{*} \mathrm{LS}\right)_{\mathrm{ikl}}=$ efeito da interação $\mathrm{j}$-ésima altura de colheita $\times \mathrm{k}$-ésimo período de coleta de amostras de silagem na desensilagem $\times 1$-ésimo estrato no silo; e $\mathrm{E}_{\mathrm{ijkl}}=$ efeito aleatório residual (Erro b).

Os dados coletados para cada variável foram submetidos à análise de variância por meio do programa estatístico SAS (SAS, 1993) e as diferenças entre as médias foram analisadas pelo teste Tukey a 5\% de significância.

A interação $(\mathrm{TP} * \mathrm{AC} * \mathrm{P} * \mathrm{LS})_{\mathrm{ijk}}$ inicialmente foi testada, no entanto, em virtude da baixa magnitude, foi removida do modelo estatístico. Os dados também foram submetidos à análise de regressão polinomial, considerando a variável período (84 dias), pelo procedimento "proc reg" do programa SAS (1993).

\section{Resultados e Discussão}

Não houve efeito $(\mathrm{P}>0,05)$ das interações entre altura de colheita, tamanho de partícula, tipo de material e período de avaliação sobre os teores de MS e PB das silagens (Tabelas 1,2 e 3). Os teores de MS diferiram entre materiais com tamanho de partícula pequeno e grande $(30,31 \mathrm{e}$ 28,98\%), com média diferencial de MS de 2,34 unidades percentuais, independentemente do tipo de material, do estrato no silo, da altura de colheita e do período de avaliação. Esse resultado pode ter sido ocasionado pela maior área de superfície de exposição das partículas finamente trituradas, o que resulta em maior desidratação das partículas, tanto durante a colheita das plantas como durante a exposição aeróbia da face frontal de corte do silo após a abertura.

Os teores de MS também diferiram $(\mathrm{P}<0,05)$ na comparação entre o material original $(30,77 \%)$ e a silagem resultante 
Tabela 1 - Composição percentual de MS, PB e FDN da planta e da silagem dos bags de acordo com o estrato no silo Table 1 - Average concentration of DM, CP, and NDF of plant and bag silage, based on particle size and cutting height according to the silo stratum

\begin{tabular}{|c|c|c|c|c|}
\hline \multirow[t]{2}{*}{$\begin{array}{l}\text { Estrato no silo } \\
\text { Silo stratum }\end{array}$} & \multirow[t]{2}{*}{$\begin{array}{c}\text { Tamanho de partícula } \\
\text { Particle size }\end{array}$} & \multicolumn{2}{|c|}{$\begin{array}{l}\text { Altura de colheita } \\
\text { Cutting height }\end{array}$} & \multirow[t]{2}{*}{$\begin{array}{l}\text { Média } \\
\text { Mean }\end{array}$} \\
\hline & & $\begin{array}{l}\text { Corte baixo } \\
\text { Low cut }\end{array}$ & $\begin{array}{l}\text { Corte alto } \\
\text { High cut }\end{array}$ & \\
\hline & & \multicolumn{3}{|c|}{ MS da planta, \% (DM of plant, \%) } \\
\hline Inferior & Partícula pequena (Small particle) & 30,82 & 33,14 & 31,98 \\
\hline Inferior & Partícula grande (Large particle) & 29,26 & 30,23 & 29,74 \\
\hline Superior & Partícula pequena (Small particle) & 31,85 & 29,93 & 30,89 \\
\hline \multirow[t]{2}{*}{ Superior } & Partícula grande (Large particle) & 30,64 & 30,66 & 30,65 \\
\hline & & \multicolumn{3}{|c|}{ MS da silagem, \% (DM of silage, \%) } \\
\hline Inferior & Partícula pequena (Small particle) & 27,41 & 29,40 & 28,40 \\
\hline Inferior & Partícula grande (Large particle) & 27,08 & 26,86 & 26,97 \\
\hline Superior & Partícula pequena (Small particle) & 29,97 & 29,93 & 29,96 \\
\hline Superior & Partícula grande (Large particle) & 29,04 & 28,06 & 28,55 \\
\hline Média geral, Est & & $28,64 b$ & $30,34 \mathrm{a}$ & \\
\hline Média geral, Est & or (Overall mean, superior stratum) & $30,37 \mathrm{a}$ & $29,64 \mathrm{ab}$ & \\
\hline
\end{tabular}

\begin{tabular}{|c|c|c|c|c|}
\hline \multirow[b]{2}{*}{ Inferior } & \multirow[b]{2}{*}{ Partícula pequena (Small particle) } & \multicolumn{3}{|c|}{ PB da planta, \% (CP of plant, \%) } \\
\hline & & 6,26 & 6,41 & 6,33 \\
\hline Inferior & Partícula grande (Large particle) & 7,60 & 6,48 & 7,04 \\
\hline Superior & Partícula pequena (Small particle) & 6,27 & 7,44 & 6,85 \\
\hline Superior & & \multicolumn{3}{|c|}{ PB da silagem, \% ( $C P$ of silage, \%) } \\
\hline Inferior & Partícula pequena (Small particle) & 5,68 & 5,79 & 5,74 \\
\hline Superior & Partícula grande (Large particle) & 5,69 & 5,30 & 5,50 \\
\hline \multirow{4}{*}{\multicolumn{2}{|c|}{$\begin{array}{l}\text { Média geral, Estrato inferior (Overall mean, inferior stratum) } \\
\text { Média geral, Estrato superior (Overall mean, superior stratum) } \\
\text { Média geral, Partícula pequena (Overall mean, small particle) } \\
\text { Média geral, Partícula grande (Overall mean, large particle) }\end{array}$}} & $6,49 a$ & \multicolumn{2}{|c|}{$6,03 \mathrm{cb}$} \\
\hline & & $5,97 \mathrm{~b}$ & \multicolumn{2}{|c|}{$6,33 \mathrm{a}$} \\
\hline & & $5,91 \mathrm{~b}$ & \multicolumn{2}{|l|}{$6,39 \mathrm{a}$} \\
\hline & & $6,55 \mathrm{a}$ & \multicolumn{2}{|l|}{$5,98 b$} \\
\hline \multirow[t]{2}{*}{ Superior } & Partícula grande (Large particle) & 55,41 & 56,87 & 56,14 \\
\hline & & \multicolumn{3}{|c|}{ FDN da silagem, \% (NDF of silage, \%) } \\
\hline Inferior & Partícula pequena (Small particle) & 58,72 & 57,30 & 58,01 \\
\hline Inferior & Partícula grande (Large particle) & 58,03 & 58,78 & 58,41 \\
\hline Superior & Partícula pequena (Small particle) & 59,29 & 54,81 & 57,05 \\
\hline Superior & Partícula grande (Large particle) & 58,62 & 59,52 & 59,07 \\
\hline \multirow{2}{*}{\multicolumn{2}{|c|}{$\begin{array}{l}\text { Média geral, Partícula pequena (Overall mean, small particle) } \\
\text { Média geral, Partícula grande (Overall mean, large particle) }\end{array}$}} & $58,72 \mathrm{a}$ & \multicolumn{2}{|l|}{$56,23 \mathrm{c}$} \\
\hline & & $56,89 \mathrm{c}$ & \multicolumn{2}{|l|}{$57,86 \mathrm{~b}$} \\
\hline
\end{tabular}

Médias seguidas de letras minúsculas diferentes diferem $(P<0,05)$ pelo teste Tukey.

Means followed by different small letters, are different $(P<0.05)$ by Tukey test.

$(29,25 \%)$, independentemente do estrato no silo, do tamanho de partícula, da altura de colheita e do período de desensilagem.

Verificou-se efeito significativo da interação altura de colheita das plantas $\times$ estrato no silo sobre o teor de MS (Tabela 1) da silagem. Silagens produzidas com plantas colhidas à altura de $15,2 \mathrm{~cm}$ tiveram menor $(\mathrm{P}<0,05)$ teor de MS no estrato inferior do silo $(28,64 \%)$ em relação às do mesmo corte no estrato superior $(30,37 \%)$ ou às silagens obtidas com plantas colhidas a $38,6 \mathrm{~cm}$ contidas tanto no estrato inferior $(29,90 \%)$ como no superior $(29,67 \%)$. Sugere-se que o processo de produção de silagem a partir da colheita das plantas, sob teores de MS inferiores a 31\%, com regulagem da ensiladeira em partículas pequenas, gere durante a compactação da massa ensilada situação de maior extravazamento de líquidos via lise celular das partículas e conseqüente precipitação destes compostos líquidos na base do silo. 
Tabela 2 - Composição percentual de nutrientes da planta de milho de acordo com o estrato no silo e o período de desensilagem

Table 2 - Average concentration of nutrients of corn plant, based on particle size and cutting height according to the silo stratum and feed-out period

\begin{tabular}{|c|c|c|c|c|c|c|}
\hline \multirow[t]{2}{*}{$\begin{array}{l}\text { Estrato } \\
\text { Stratum }\end{array}$} & \multirow[t]{2}{*}{$\begin{array}{c}\text { Tamanho de partícula } \\
\text { Particle size }\end{array}$} & \multirow[t]{2}{*}{$\begin{array}{l}\text { Altura de colheita } \\
\text { Cutting height }\end{array}$} & \multicolumn{4}{|c|}{$\begin{array}{l}\text { Período de desensilagem } \\
\text { Feed-out period }\end{array}$} \\
\hline & & & $\begin{array}{c}24 / 08 \text { a } 14 / 09 \\
24 / 08 \text { to } 14 / 09\end{array}$ & $\begin{array}{l}15 / 09 \text { a } 05 / 10 \\
15 / 09 \text { to } 05 / 10\end{array}$ & $\begin{array}{c}06 / 10 \text { a } 26 / 10 \\
06 / 10 \text { to } 26 / 10\end{array}$ & $\begin{array}{l}27 / 10 \text { a } 16 / 11 \\
27 / 10 \text { to } 16 / 11\end{array}$ \\
\hline & & & \multicolumn{4}{|c|}{ MS da planta, \% (DM of plant, \%) } \\
\hline $\begin{array}{l}\text { Inferior } \\
\text { Inferior }\end{array}$ & $\begin{array}{l}\text { Pequena (Small) } \\
\text { Grande (Large) } \\
\text { Pequena (Small) } \\
\text { Grande (Large) }\end{array}$ & $\begin{array}{l}\text { Baixa (Low) } \\
\text { Baixa (Low) } \\
\text { Alta (High) } \\
\text { Alta (High) }\end{array}$ & $\begin{array}{l}31,35 \\
29,64 \\
33,28 \\
30,11\end{array}$ & $\begin{array}{l}30,77 \\
29,67 \\
33,06 \\
30,46\end{array}$ & $\begin{array}{l}30,85 \\
28,59 \\
33,11 \\
29,78\end{array}$ & $\begin{array}{l}30,31 \\
29,13 \\
33,11 \\
30,56\end{array}$ \\
\hline $\begin{array}{l}\text { Superior } \\
\text { Superior }\end{array}$ & $\begin{array}{l}\text { Pequena (Small) } \\
\text { Grande (Large) } \\
\text { Pequena (Small) } \\
\text { Grande (Large) }\end{array}$ & $\begin{array}{l}\text { Baixa (Low) } \\
\text { Baixa (Low) } \\
\text { Alta (High) } \\
\text { Alta (High) }\end{array}$ & $\begin{array}{l}31,65 \\
30,46 \\
30,12 \\
31,16\end{array}$ & $\begin{array}{l}32,01 \\
30,66 \\
29,15 \\
31,17\end{array}$ & $\begin{array}{l}31,16 \\
30,50 \\
29,11 \\
30,86\end{array}$ & $\begin{array}{l}32,58 \\
30,94 \\
31,35 \\
30,43\end{array}$ \\
\hline \multicolumn{3}{|c|}{ Média geral (Overall mean) } & $30,97 \mathrm{a}$ & $30,87 \mathrm{a}$ & $30,50 \mathrm{a}$ & $31,05 \mathrm{a}$ \\
\hline Inferior & $\begin{array}{l}\text { Pequena (Small) } \\
\text { Grande (Large) }\end{array}$ & $\begin{array}{l}\text { Alta (High) } \\
\text { Alta (High) }\end{array}$ & $\begin{array}{l}6,49 \\
6,37\end{array}$ & $\begin{array}{l}6,83 \\
6,43\end{array}$ & $\begin{array}{l}6,05 \\
6,43\end{array}$ & $\begin{array}{l}6,28 \\
6,69\end{array}$ \\
\hline $\begin{array}{l}\text { Superior } \\
\text { Superior }\end{array}$ & $\begin{array}{l}\text { Pequena (Small) } \\
\text { Grande (Large) } \\
\text { Pequena (Small) } \\
\text { Grande (Large) }\end{array}$ & $\begin{array}{l}\text { Baixa (Low) } \\
\text { Baixa (Low) } \\
\text { Alta (High) } \\
\text { Alta (High) }\end{array}$ & $\begin{array}{l}6,09 \\
6,68 \\
7,51 \\
6,24\end{array}$ & $\begin{array}{l}6,05 \\
6,75 \\
7,44 \\
6,47\end{array}$ & $\begin{array}{l}6,84 \\
6,15 \\
7,38 \\
7,18\end{array}$ & $\begin{array}{l}6,10 \\
6,37 \\
7,42 \\
6,71\end{array}$ \\
\hline \multicolumn{3}{|c|}{ Média geral (Overall mean) } & $6,64 \mathrm{a}$ & $6,74 \mathrm{a}$ & $6,80 \mathrm{a}$ & $6,61 \mathrm{a}$ \\
\hline & & & \multicolumn{4}{|c|}{ FDN da planta, \% (NDF of plant, \%) } \\
\hline $\begin{array}{l}\text { Inferior } \\
\text { Inferior }\end{array}$ & $\begin{array}{l}\text { Pequena (Small) } \\
\text { Grande (Large) } \\
\text { Pequena (Small) } \\
\text { Grande (Large) }\end{array}$ & $\begin{array}{l}\text { Baixa (Low) } \\
\text { Baixa (Low) } \\
\text { Alta (High) } \\
\text { Alta (High) }\end{array}$ & $\begin{array}{l}55,23 \\
52,28 \\
53,25 \\
55,53\end{array}$ & $\begin{array}{l}53,83 \\
50,37 \\
51,15 \\
51,08\end{array}$ & $\begin{array}{l}55,96 \\
53,21 \\
53,36 \\
51,40\end{array}$ & $\begin{array}{l}55,89 \\
52,34 \\
52,91 \\
52,41\end{array}$ \\
\hline
\end{tabular}

Médias na linha seguidas de letras minúsculas diferentes diferem entre si $(P<0,05)$ pelo teste Tukey.

Means within the same row followed by different small letters are different $(P<0.05)$ by Tukey test.

Diferenças significativas foram observadas nos teores de PB (Tabela 1) na comparação entre material original $(6,71 \%)$ e a silagem $(5,59 \%)$, comprovando, em média, diferencial de $\mathrm{PB}$ de 1,13 unidades percentuais, independentemente do estrato no silo, do tamanho de partícula, da altura de colheita e do período de desensilagem (Tabelas 1 e 2). Interações significativas de altura de colheita das plantas e estrato no silo e de tamanho de partícula e estrato no silo também foram observadas. Silagens manipuladas a partir da altura de colheita das plantas em $15,2 \mathrm{~cm}$ no estrato inferior do silo $(6,49 \%)$ ou em $38,6 \mathrm{~cm}$ no estrato superior do silo (6,33\%) apresentaram maiores teores de PB em relação àquelas obtidas a $15,2 \mathrm{~cm}$ e contida no estrato superior $(5,97 \%)$ ou àquelas obtidas a $38,6 \mathrm{~cm}$ contidas no estrato inferior $(6,03 \%)$ do silo. Na análise do tamanho de partícula, silagens de partículas pequenas no estrato inferior do silo $(6,03 \%)$ ou com tamanho de partículas grandes no estrato superior do silo $(6,03 \%)$ tiveram menores $(\mathrm{P}<0,05)$ teores de $\mathrm{PB}$ em relação às silagens de partículas pequenas contidas no estrato superior $(6,26 \%)$ ou silagens de partículas grandes contidas no estrato inferior $(6,49 \%)$.

Observou-se também interação significativa de altura de colheita das plantas e tamanho de partícula para o teor de PB. Silagens manipuladas considerando a altura de colheita das plantas em $15,2 \mathrm{~cm}$ com partículas pequenas $(5,91 \%)$ ou a $38,6 \mathrm{~cm}$ de altura com partículas grandes $(5,98 \%)$ apresentaram menores teores de $\mathrm{PB}(\mathrm{P}<0,05) \mathrm{em}$ relação àquelas manipuladas a $15,2 \mathrm{~cm}$ de altura de colheita com partículas grandes $(6,55 \%)$ ou a $38,6 \mathrm{~cm}$ com partículas pequenas $(6,39 \%)$. 
Tabela 3 - Composição percentual de nutrientes da silagem de milho de acordo com o estrato no silo e o período de desensilagem Table 3 - Average concentration of nutrients of corn silage, based on particle size and cutting height according to the silo strato and feed-out period

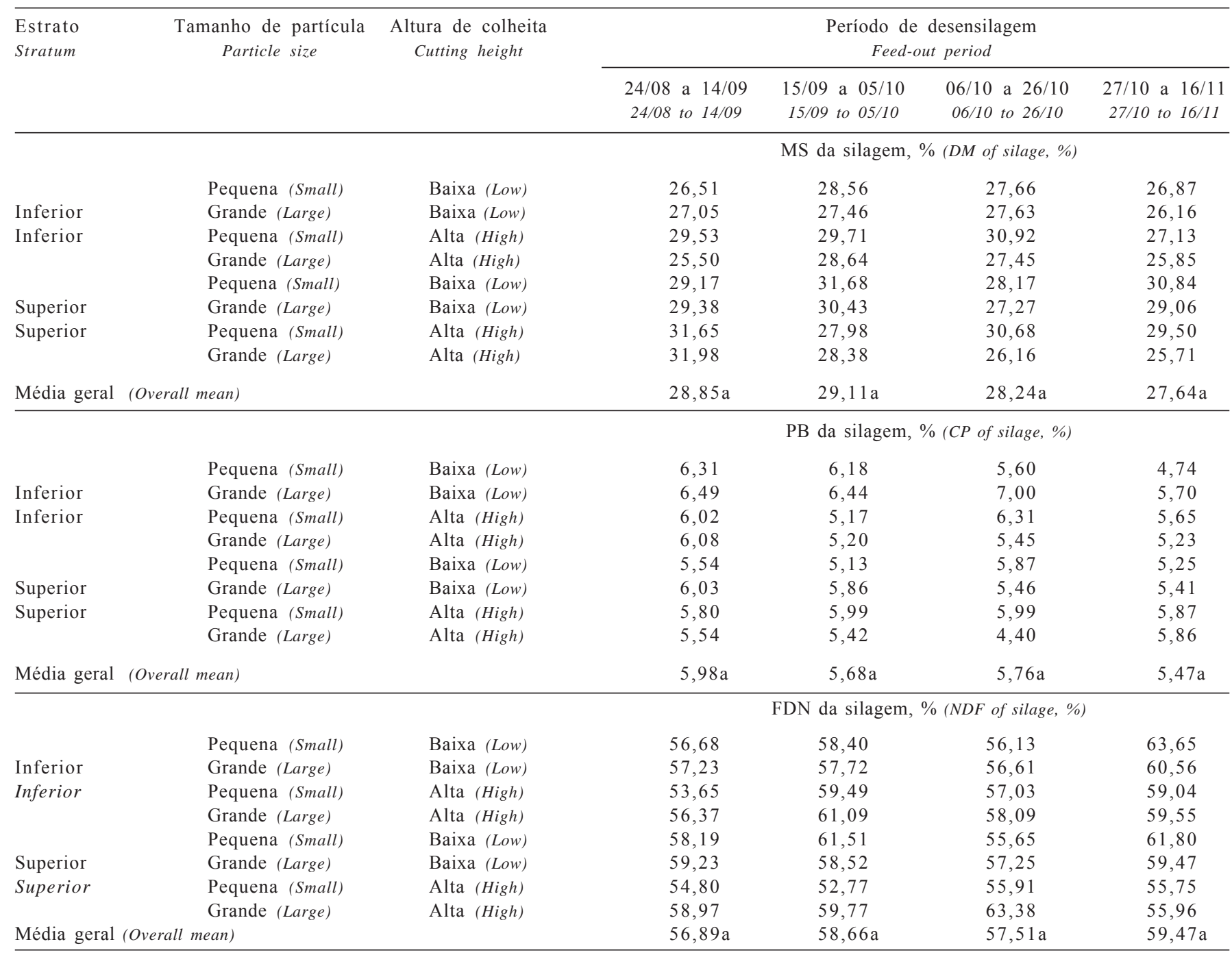

Médias na linha seguidas por letras minúsculas diferentes diferem entre si $(P<0,05)$ pelo teste Tukey.

Means within a row followed by different small letters are different $(P<0.05)$ by Tukey test.

Os teores de FDN tiveram resposta análoga aos fatores de variação, comprovando diferença significativa na comparação entre material original e silagem resultante $(56,71$ vs $58,14 \%)$.

Houve efeito significativo da interação entre altura de colheita das plantas e tamanho de partícula sobre o teor de FDN das silagens (Tabela 1). Os teores de FDN de silagens manipuladas considerando a altura de colheita das plantas em $15,2 \mathrm{~cm}$ com partículas pequenas $(58,72 \%)$ foram maiores que o daquelas manipuladas com essa mesma altura, porém, com partículas grandes $(56,89 \%)$ ou a $38,6 \mathrm{~cm}$ de altura com partículas pequenas $(56,23 \%)$. Essas silagens não diferiram daquela obtida a $38,6 \mathrm{~cm}$ de altura com partículas grandes $(57,87 \%)$.

O período de desensilagem, de forma individual ou combinada com os fatores altura de colheita, tamanho de partícula, tipo de material e estrato no silo, não influenciou os teores de MS, PB e FDN da planta e da silagem (Tabelas 2 e 3). Segundo Evangelista et al. (2004), para alguns parâmetros, não ocorrem alterações significativas durante o processo de fermentação, como os teores de MS, PB, amido, celulose e lignina e nos coeficientes de digestibilidade in vitro da MS. Guimarães Jr. et al. (2005), avaliando silagens de diferentes variedades de milheto, em diferentes tempos de fermentação $(1,3,5,7,14,28$ e 56 dias), em silos de laboratório do tipo PVC, verificaram que os conteúdos de MS e PB mantiveram-se estáveis durante o processo fermentativo.

O processo de desensilagem é afetado principalmente pela desestruturação da massa, com conseqüente entrada de $\mathrm{O}_{2}$ e ativação dos processos químicos, físicos e microbiológicos que atuam em detrimento ao valor nutri- 
tivo da silagem (McDonald et al., 1991). A maioria dos trabalhos realizados para avaliação do processo fermentativo de silagens refere-se ao estudo do processo em diferentes tempos de fermentação da massa estruturada no silo, ou seja, ainda ensilada. Entretanto, existem poucos estudos considerando as alterações decorrentes de oxidação e aquelas resultantes da atividade microbiana durante a desensilagem da massa quando exposta às condições aeróbias durante o período de tempo de uso do material na alimentação de ruminantes. Neumann et al. (2002) inferem que o teor de MS no decorrer do processo de ensilagem pode variar por fatores de ordem técnica, relacionados à regulagem da ensiladeira em altura de corte e ao tamanho de partícula na colheita, à distância de transporte entre lavoura e silo, ao tempo de enchimento, ao sistema de compactação e à vedação do silo no decorrer do processo de confecção da silagem. Neste trabalho os teores de MS, PB e FDN das silagens de milho modificaram-se no interior do silo sob efeitos associativos da altura de colheita, do tamanho de partícula e do estrato no silo, porém, mantiveram-se estáveis ao longo do período de desensilagem.

Interações significativas de altura de colheita das plantas e estrato no silo $(\mathrm{P}<0,05)$ e de tamanho de partícula e estrato no silo $(\mathrm{P}<0,10)$ foram observadas, respectivamente para as perdas de MS e de PB (Tabela 4). Silagens manipuladas a partir da altura de colheita das plantas em $38,6 \mathrm{~cm}$ no estrato inferior $(4,91 \%)$ tiveram maiores perdas em relação ao estrato superior no silo $(2,67 \%)$ e àquelas produzidas com plantas colhidas a $15,2 \mathrm{~cm}$ independentemente do estrato no silo. $\mathrm{Na}$ análise das perdas de $\mathrm{PB}$, as perdas observadas em silagens de tamanho de partículas pequenas no estrato superior $(18,96 \%)$ e silagens de partículas grandes no estrato inferior $(18,68 \%)$ foram maiores que as observadas nas silagens com partículas pequenas no estrato inferior $(11,52 \%)$ e silagens de partículas grandes no estrato superior $(17,54 \%)$.

Não houve interações $(\mathrm{P}>0,05)$ dos fatores altura de colheita, tamanho de partícula, tipo de material e período de desensilagem para as perdas de FDN (Tabela 4), que foram maiores nas silagens com partículas pequenas em relação àquelas com partículas grandes ( 3,05 vs $-0,38 \%)$.

Almeida Filho et al. (1999), comparando forragem original e silagem de diferentes híbridos de milho, observaram diminuição nos teores de FDN durante o processo de ensilagem do milho, fato associado, segundo estes autores, à hidrólise da fração hemicelulose, enquanto, para os teores de FDA, observaram variação heterogênea,

Tabela 4 - Perdas de nutrientes em silagens nos diferentes estratos do silo

Table 4 - Losses of nutrients based on the particle size and cutting height, according to the silo stratum

\begin{tabular}{|c|c|c|c|}
\hline \multirow{2}{*}{$\begin{array}{l}\text { Estrato no silo } \\
\text { Silo stratum }\end{array}$} & \multirow{2}{*}{$\begin{array}{c}\text { Tamanho de partícula } \\
\text { Particle size }\end{array}$} & Altu & \multirow{2}{*}{$\begin{array}{l}\text { Média } \\
\text { Mean }\end{array}$} \\
\hline & & & \\
\hline
\end{tabular}

Perdas de MS, \% (Losses of DM, \%)

\begin{tabular}{|c|c|c|c|c|}
\hline Inferior & Partícula pequena (Small particle) & 2,25 & 4,80 & 3,52 \\
\hline \multirow[t]{2}{*}{ Inferior } & Partícula grande (Large particle) & 4,04 & 5,03 & 4,53 \\
\hline & Média (Mean) & $3,15 \mathrm{bc}$ & $4,91 \mathrm{a}$ & \\
\hline Superior & Partícula pequena (Small particle) & 5,40 & 1,82 & 3,61 \\
\hline \multirow[t]{2}{*}{ Superior } & Partícula grande (Large particle) & 2,70 & 3,53 & 3,11 \\
\hline & Média (Mean) & $3,79 b$ & $2,67 \mathrm{c}$ & \\
\hline
\end{tabular}

Perdas de PB, \% (Losses of $C P, \%$ )

\begin{tabular}{|c|c|c|c|c|}
\hline Inferior & Partícula pequena (Small particle) & 9,74 & 13,31 & $11,52 \mathrm{c}$ \\
\hline \multirow[t]{2}{*}{ Inferior } & Partícula grande (Large particle) & 18,53 & 18,84 & $18,68 \mathrm{a}$ \\
\hline & Média (Mean) & 14,13 & 16,07 & \\
\hline Superior & Partícula pequena (Small particle) & 16,15 & 21,78 & $18,96 \mathrm{a}$ \\
\hline \multirow[t]{2}{*}{ Superior } & Partícula grande (Large particle) & 13,91 & 21,18 & $17,54 b$ \\
\hline & Média (Mean) & 15,03 & 21,48 & \\
\hline
\end{tabular}

Perdas de FDN, \% (Losses of NDF, \%)

\begin{tabular}{|c|c|c|c|c|}
\hline Inferior & Partícula pequena (Small particle) & 3,38 & 2,19 & $2,78 \mathrm{a}$ \\
\hline \multirow[t]{2}{*}{ Inferior } & Partícula grande (Large particle) & $-0,55$ & 0,84 & $0,15 b$ \\
\hline & Média (Mean) & 1,41 & 1,51 & \\
\hline Superior & Partícula pequena (Small particle) & 1,29 & 5,36 & $3,33 \mathrm{a}$ \\
\hline \multirow[t]{2}{*}{ Superior } & Partícula grande (Large particle) & $-3,11$ & 1,27 & $-0,92 b$ \\
\hline & Média (Mean) & $-0,91$ & 3,31 & \\
\hline
\end{tabular}

Médias seguidas de letras minúsculas diferentes, para cada variável, diferem $(P<0,05)$ pelo teste Tukey. 
com decréscimos ou acréscimos de valores na comparação dos diferentes cultivares.

Não houve interação $(P>0,05)$ de período de desensilagem, altura de colheita, tamanho de partícula, tipo de material e estrato no silo para as perdas (Pe) de MS, PB e FDN (Tabela 5). No entanto, verificou-se diferença estatística entre períodos de avaliação para as perdas de MS, PB e FDN. As perdas de MS da massa ensilada sofreram efeito quadrático, com ponto de mínimas perdas (2,24\%) aos 41,70 dias de uso do silo (Tabela 5).
As perdas de $\mathrm{PB}$ da silagem durante a desensilagem foram instáveis, com comportamento crescente de $0,14 \%$ por dia, mostrando, segundo equação de regressão, linearidade no aumento nas perdas de 9,12 para $21,21 \%$, respectivamente, ao longo do $1^{\mathrm{O}}$ ao $84^{\mathrm{o}}$ dia de uso do silo na alimentação dos animais.

Watson \& Nash (1960), analisando 800 experimentos, relataram perdas de MS e de nitrogênio $(\mathrm{N})$ durante a ensilagem em torno de 16,1 e $15,2 \%$, respectivamente. Zimmer (1967), utilizando dados de perdas de MS de 504

Tabela 5 - Perdas de nutrientes nos estratos do silo e nos períodos de desensilagem

Table 5 - Losses of nutrients based on the particle size and cutting height according to the silo stratum and feed-out period

\begin{tabular}{|c|c|c|c|c|c|c|}
\hline \multirow{3}{*}{$\begin{array}{l}\text { Estrato } \\
\text { Stratum }\end{array}$} & \multicolumn{2}{|c|}{$\begin{array}{l}\text { Ensilagem } \\
\text { Silage }\end{array}$} & & & & \\
\hline & \multirow[t]{2}{*}{$\begin{array}{c}\text { Tamanho de partícula } \\
\text { Particle size }\end{array}$} & \multirow[t]{2}{*}{$\begin{array}{l}\text { Altura de colheita } \\
\text { Cutting height }\end{array}$} & \multicolumn{4}{|c|}{$\begin{array}{c}\text { Período de desensilagem } \\
\text { Feed-out period }\end{array}$} \\
\hline & & & $\begin{array}{c}24 / 08 \text { a } 14 / 09 \\
24 / 08 \text { to } 14 / 09\end{array}$ & $\begin{array}{l}15 / 09 \text { a } 05 / 10 \\
15 / 09 \text { to } 05 / 10\end{array}$ & $\begin{array}{c}06 / 10 \text { a } 26 / 10 \\
06 / 10 \text { to } 26 / 10\end{array}$ & $\begin{array}{r}27 / 10 \text { a } 16 / \\
27 / 10 \text { to } 16 /\end{array}$ \\
\hline & & & \multicolumn{4}{|c|}{ Perdas de MS, \% (Losses of DM, \%) } \\
\hline & Pequena (Small) & Baixa (Low) & 3,29 & 0,92 & 0,67 & 4,10 \\
\hline Inferior & Grande (Large) & Baixa (Low) & 2,13 & 5,20 & 0,85 & 7,97 \\
\hline \multirow[t]{3}{*}{ Inferior } & Pequena (Small) & Alta (High) & 4,18 & 2,23 & 4,00 & 8,81 \\
\hline & Grande (Large) & Alta (High) & 4,69 & 6,60 & 2,28 & 6,56 \\
\hline & Pequena (Small) & Baixa (Low) & 7,58 & 0,50 & 5,40 & 8,10 \\
\hline Superior & Grande (Large) & Baixa (Low) & 1,00 & 0,23 & 3,62 & 5,94 \\
\hline \multirow[t]{3}{*}{ Superior } & Pequena (Small) & Alta (High) & 0,02 & 3,39 & 0,90 & 3,00 \\
\hline & Grande (Large) & Alta (High) & 1,54 & 0,96 & 7,03 & 4,60 \\
\hline & \multicolumn{2}{|c|}{ Média geral (Overall mean) } & 3,05 & 2,50 & 3,09 & 6,14 \\
\hline
\end{tabular}

Equação regressão* (Regression equation): PeMS (LoDM) $=5,7197-0,1668 \mathrm{D}+0,0020 \mathrm{D}^{2}\left(\mathrm{R}^{2}: 0,0950 ; \mathrm{CV}: 20,66 \% ; \mathrm{P}<0,0097\right)$

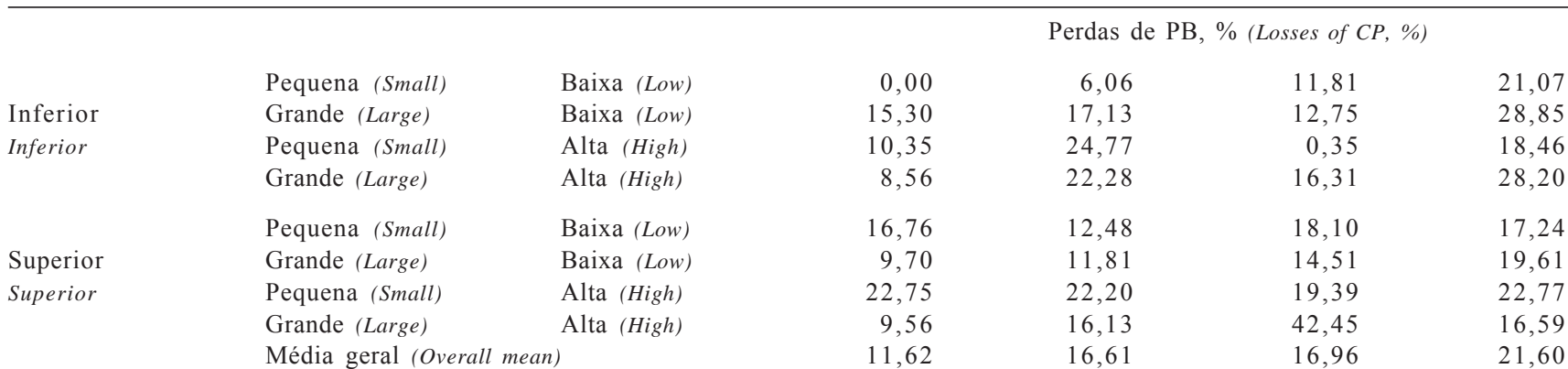

Equação de regressão (Regression equation): $\mathrm{PePB}\left(\right.$ LoCP) $=9,1219+0,1439 \mathrm{D}\left(\mathrm{R}^{2}: 0,0579 ; \mathrm{CV}: 18,41 \% ; \mathrm{P}<0,0182\right)$

\begin{tabular}{|c|c|c|c|c|c|c|}
\hline & & & \multicolumn{4}{|c|}{ Perdas de FDN, \% (Losses of NDF, \%) } \\
\hline & Pequena (Small) & Baixa (Low) & 7,29 & 0,90 & 7,04 & $-1,30$ \\
\hline Inferior & Grande (Large) & Baixa (Low) & $-1,37$ & $-2,12$ & 1,63 & $-0,34$ \\
\hline \multirow[t]{3}{*}{ Inferior } & Pequena (Small) & Alta (High) & 9,30 & $-8,16$ & 2,92 & 4,70 \\
\hline & Grande (Large) & Alta (High) & 9,03 & $-3,98$ & $-2,31$ & 0,64 \\
\hline & Pequena (Small) & Baixa (Low) & 8,12 & $-10,27$ & 7,31 & 0,01 \\
\hline Superior & Grande (Large) & Baixa (Low) & $-7,36$ & $-6,05$ & 2,24 & $-1,27$ \\
\hline \multirow[t]{3}{*}{ Superior } & Pequena (Small) & Alta (High) & 2,98 & 11,23 & 6,45 & 0,76 \\
\hline & Grande (Large) & Alta (High) & $-0,20$ & $-0,80$ & $-9,43$ & 5,34 \\
\hline & \multicolumn{2}{|c|}{ Média geral (Overall mean) } & 3,47 & $-2,41$ & 1,98 & 1,08 \\
\hline
\end{tabular}

Equação regressão $(L o D M): \operatorname{PeFDN}(L o N D F)=7,9429-0,3091 \mathrm{D}+0,0028 \mathrm{D}^{2}\left(\mathrm{R}^{2}: 0,0220 ; \mathrm{CV}: 42,79 \% ; \mathrm{P}<0,3548\right)$

* $\mathrm{D}=$ período de desensilagem variando de 1 a 84 dias $\left({ }^{*} D=\right.$ Feed-out period of 1 to 84 days). 
experimentos, envolvendo diferentes forrageiras com diferentes teores de MS na colheita, encontrou valores de 0,8 a $71,0 \%$, com média de $19,4 \%$.

Observou-se comportamento quadrático para as perdas de FDN, com ponto de mínimas perdas, representado pelo aumento dos teores de FDN $(0,60 \%)$ na MS da silagem em relação à forragem original aos 55,20 dias de uso do silo.

Segundo Reis \& Jobim (2001), a elevação nos valores de FDA pode ser explicada pelo efeito de diluição, pois, com o decréscimo nos conteúdos dos carboidratos solúveis e de hemicelulose (FDN) e a pequena diminuição de FDA, ocorre elevação proporcional destes valores, uma vez que os dados são expressos em \% da MS. Senger et al. (2005), sob condições de compactação adequada $\left(700 \mathrm{~kg} / \mathrm{m}^{3}\right.$ de MV) e compactação deficiente $\left(400 \mathrm{~kg} / \mathrm{m}^{3}\right.$ de MV), verificaram que, em silagens de milho com elevado teor de umidade (20\% de MS), os teores de FDN da silagem foram superiores ao da forragem fresca, possivelmente em virtude da perda de açúcares solúveis, causando aumento dos carboidratos fibrosos, enquanto, em silagens com menor teor de umidade (26 a 28\% de MS), os teores de FDN diminuíram com o processo de ensilagem em relação à forragem fresca, em decorrência da redução da fração de hemicelulose consumida durante a fermentação.

Neste trabalho (Tabelas 4 e 5), as perdas de MS, PB e FDN ocorreram em proporções diferenciadas e análogas sob efeitos associativos dos fatores altura de colheita e tamanho de partícula com estrato no silo e período de desensilagem, indicando que os processos de fermentação, de oxidação e de re-fermentação são heterogêneos na massa ensilada. Essa afirmações podem ser justificados pela menor $(\mathrm{P}<0,05)$ eficiência de compactação no estrato superior em relação ao estrato inferior $\left(432,5\right.$ e $532,9 \mathrm{~kg} / \mathrm{m}^{3}$ de MV e 120,3 e $147,0 \mathrm{~kg} / \mathrm{m}^{3}$ de MS), respectivamente, o que favoreceu a permanência de oxigênio na massa neste estrato, sugerindo que a presença de oxigênio na massa localizada no estrato superior durante a ensilagem proporcionou respiração das partículas ensiladas diminuindo a concentração de compostos solúveis e energia, limitando também o crescimento microbiano, assim como definiu condição de maiores temperatura da massa $\left(29,14\right.$ vs $\left.26,84^{\circ} \mathrm{C}\right)$, diferencial de temperatura entre a silagem e meio ambiente $(8,22$ vs $\left.5,93^{\circ} \mathrm{C}\right), \mathrm{pH}(4,08$ vs 3,97$)$ e $\mathrm{N}-\mathrm{NH}_{3} / \mathrm{NT}(2,77$ vs $2,31 \%)$ na silagem contida no estrato superior do silo, independentemente da altura de colheita e do tamanho de partículas, comparativamente ao estrato inferior dos silos.

A interação altura de colheita $\times$ tamanho de partícula não influenciou $(\mathrm{P}>0,05)$ as perdas físicas de silagem, com base na MV e na MS (Tabela 6).

As perdas de material durante a desensilagem e alimentação dos animais, expressas com base na MV e MS, respectivamente, foram semelhantes na comparação da colheita das plantas à altura de $15,2 \mathrm{~cm}(2,16$ e 2,32\%) à altura de $38,6 \mathrm{~cm}(1,84$ e $2,10 \%)$.

A exposição da silagem ao ar, após a abertura do silo e durante o fornecimento aos animais, resultou em perdas econômicas decorrentes da perda de MS. A silagem resultante do processo de colheita com tamanho de partícula grande determinou maiores ocorrências de perdas físicas, expressas com base na MV $(2,59$ e $1,41 \%)$ e na MS $(2,91$ e

Tabela 6 - Perdas físicas de silagem (\%), com base na matéria verde (MV) e na matéria seca (MS), durante a desensilagem Table 6 - $\quad$ Physical losses of silage (\%) on fresh matter (FM) and DM basis, during feed-out period, based on particle size and cutting height

\begin{tabular}{|c|c|c|c|}
\hline \multirow[t]{2}{*}{$\begin{array}{l}\text { Ensilagem } \\
\text { Silage }\end{array}$} & \multicolumn{2}{|c|}{$\begin{array}{l}\text { Altura de colheita } \\
\text { Cutting height }\end{array}$} & \multirow[t]{2}{*}{$\begin{array}{l}\text { Média } \\
\text { Mean }\end{array}$} \\
\hline & $\begin{array}{l}\text { Corte baixo } \\
\text { Low cut }\end{array}$ & $\begin{array}{l}\text { Corte alto } \\
\text { High cut }\end{array}$ & \\
\hline & \multicolumn{2}{|c|}{$\begin{array}{l}\text { Perdas físicas, \% na MV } \\
\text { Physical losses (\% of FM) }\end{array}$} & \\
\hline Média (Mean) & \multicolumn{2}{|c|}{$\begin{array}{l}\text { Perdas físicas, \% na MS } \\
\text { Physical losses (\% of DM) }\end{array}$} & \\
\hline $\begin{array}{l}\text { Partícula pequena (Small particle) } \\
\text { Partícula grande (Large particle) } \\
\text { Média (Mean) }\end{array}$ & $\begin{array}{l}1,60 \\
3,05 \\
2,32 \mathrm{~A}\end{array}$ & $\begin{array}{l}1,42 \\
2,78 \\
2,10 \mathrm{~A}\end{array}$ & $\begin{array}{l}1,51 \mathrm{~A} \\
2,91 \mathrm{~B}\end{array}$ \\
\hline
\end{tabular}

Médias na linha ou na coluna seguidas de letras maiúsculas diferentes diferem $(P<0,05)$ pelo teste $F$. Means within a row or a column followed by different capital letters are different $(P<0.05)$ by F test. 
$1,51 \%)$ em relação à partícula pequena. Essa resultado pode ser justificado pela susceptibilidade das silagens com partículas grandes à deterioração após abertura dos silos, possivelmente em virtude da menor compactação destas silagens quando associadas às temperaturas elevadas do meio ambiente.

\section{Conclusões}

As perdas de MS, PB e FDN ocorreram em proporções diferenciadas e análogas sob efeitos associativos da altura de colheita e do tamanho de partícula com o estrato no silo, de forma crescente ao longo do tempo de utilização das silagens. Na silagem com partículas grandes, ocorreram maiores perdas físicas na desensilagem e durante a alimentação dos animais. Recomenda-se a colheita da planta de milho à altura de $38,6 \mathrm{~cm}$ e tamanho de partícula entre $0,2 \mathrm{e}$ $0,6 \mathrm{~cm}$, por determinar menores perdas físicas e nutricionais na desensilagem. A maior deterioração das silagens de milho ocorreu no estrato superior do silo, em decorrência da elevação da temperatura e dos maiores índices de $\mathrm{pH}$ em relação ao estrato inferior.

\section{Literatura Citada}

ALMEIDA FILHO, S.L.; FONSECA, D.M.; GARCIA, R. et al. Características agronômicas de cultivares de milho (Zea mays L.) e qualidade dos componentes e das silagens. Revista Brasileira de Zootecnia, v.28, n.1, p.7-13, 1999.

ASSOCIATION OF OFFICIAL ANALYTICAL CHEMISTS - AOAC. Official methods of analysis. 16.ed. Washington: AOAC, 1995. 2000p.

BALSALOBRE, M.A.A.; NUSSIO, L.G.; MARTHA JR., G.B. Controle de perdas na produção de silagens de gramíneas tropicais. In: REUNIÃO ANUAL DA SOCIEDADE BRASILEIRA DE ZOOTECNIA, 38., 2001, Piracicaba. Anais... Piracicaba, 2001. p.890-911.

EVANGElista, A.R.; ABREU, J.G.; PEREIRA, R.C. Perdas na conservação de forragens. In: JOBIM, C.C. et al. (Ed.) SIMPÓSIO SOBRE PRODUÇÃO E UTILIZAÇÃO DE FORRAGENS CONSERVADAS, 2., 2004, Maringá. Anais... Maringá: Universidade Estadual de Maringá, 2004. p.75-112.
GUIMARÃES JR., R.; GONÇALVES, L.C.; RODRIGUES, J.A.S. et al. Matéria seca, proteína bruta, nitrogênio amoniacal e $\mathrm{pH}$ das silagens de três genótipos de milheto [Pennisetum glaucum (L). R. BR.], em diferentes períodos de fermentação. Revista Brasileira de Milho e Sorgo, v.4, n.2, p.251-258, 2005.

McDONALD. P. The biochemistry of silage. New York: Interscience Publication: John Willey, 1991. 226p.

McDONALD, P.; HENDERSON, N.; HERON, S. The biochemistry of silage. 2.ed. Marlow: Chalcombe, 1991. 339p.

MUHLBACH, P.R.F. Silagem: produção com controle de perdas. In: LOBATO, J.F.P.; BARCELOS, J.O.J.; HESSLER, A.M. (Eds.) Produção de bovinos de corte. Porto Alegre: Pontíficia Universidade Católica, 1999. p.97-120.

NEUMANN, M.; RESTLE, J.; ALVES FILHO, D.C. et al. Avaliação do valor nutritivo da planta e da silagem de diferentes híbridos de sorgo (Sorghum bicolor, L. Moench). Revista Brasileira de Zootecnia, v.31, n.1, p.293-301, 2002 (supl. 1).

RECOMENDAÇÕES DA COMISSÃO DE FERTILIDADE DO SOLO - RS/SC. Recomendações de adubação e calagem para os Estados do Rio Grande do Sul e Santa Catarina. 3ed. Passo Fundo: SBCS-Núcleo Regional Sul : EMBRAPA-CNPT, 1995. $223 \mathrm{p}$.

REIS, R.A.; JOBIM, C.C. Perfil da fração de carboidratos da planta e adequação de aditivos no processo de ensilagem. In: WORKSHOP SOBRE MILHO PAR SILAGEM, 2., Piracicaba, 2001. Anais... Piracicaba: Fundação de Estudos Agrários Luiz de Queiroz, 2001.p.27-52.

STATISTICAL ANALYSIS SYSTEM - SAS. SAS/STAT user's Guide: statistics, version 6. 4.ed. North Caroline: 1993. v.2, $943 \mathrm{p}$.

SENGER, C.C.D.; MUHLBACH, P.R.F.; SÁNCHEZ, L.M.B. et al. Composição química e digestibilidade "in vitro" de silagem de milho com distintos teores de umidade e níveis de compactação. Ciência Rural, v.35, n.6, p.1393-1399, 2005.

Van SOEST, P.J.; ROBERTSON, J.B.; LEWIS, B.A. Symposium: Carbohydrate methodology, metabolism, and nutritional implications in dairy cattle. Methods for dietary fiber, neutral detergent fiber, and nonstarch polysaccharides in relation to animal nutrition. Journal of Dairy Science, v.74, n.10, p.3583-3597, 1991.

WATSON, S.J.; NASH, M.J. The conservation of grass and forage crops. Edinburgh: Oliver and Boyd, 1960. 90p.

ZIMMER, E. Factors affecting silage fermentation, in silo. Das Wirtschaftseigene Futter, v.13, p.271-286, 1967. 